\title{
Preface
}

\section{Studies on marine dynamic disasters}

\author{
HU Po ${ }^{1,2,3,4}$, LIU Yahao ${ }^{1,2,4}$, HOU Yijun ${ }^{1,2,3,4, *}$ \\ ${ }^{I}$ Key Laboratory of Ocean Circulation and Waves, Institute of Oceanology, Chinese Academy of Sciences, Qingdao 266071, \\ China \\ ${ }^{2}$ Center for Ocean Mega-Science, Chinese Academy of Sciences, Qingdao 266071, China \\ ${ }^{3}$ University of Chinese Academy of Sciences, Beijing 100049, China \\ ${ }^{4}$ Laboratory for Ocean and Climate Dynamics, Qingdao National Laboratory for Marine Science and Technology, Qingdao \\ 266237, China \\ Received Aug. 29, 2019; accepted for publication Sep. 10, 2019 \\ (C) Chinese Society for Oceanology and Limnology, Science Press and Springer-Verlag GmbH Germany, part of Springer Nature 2019
}

Marine dynamic disasters, including storm surges, huge waves, and sea ice, are the most harmful natural disasters affecting coastal countries in the world. Under the influence of global climate change, the mechanisms, frequencies, and damage severity of marine dynamic disasters are exhibiting new characteristics. The enormity, unpredictability, and chain effects of these disasters have become increasingly prominent, and the losses endured by coastal countries around the world have been increasing year by year. Therefore, the prediction of, risk assessment for, and emergency response to marine dynamic disasters are important issues for disaster prevention and mitigation worldwide.

With the development of computer technology, the numerical prediction of and early warning technology for marine dynamic disasters have been evolving since the 1970s. By the 1990s, a relatively advanced forecasting and early warning system had been formed in developed countries such as the United States, Europe, and Japan (Blain et al., 1994; DHI, 1996; Wilson and Chen, 1997; Hubbert and McInnes, 1999). By the end of the twentieth century, natural disaster risk assessment had become a hot topic in disaster prevention and mitigation in all countries. Disaster risk, vulnerability, and impact assessments have been identified as some of the highest priorities in international disaster reduction strategy (IPCC, 2014). The National Oceanic and Atmospheric Administration (NOAA) and the National Hurricane Center (NHC) of the United States have conducted storm surge risk assessment since the 1990s. These organizations primarily study storm surges caused by tropical cyclones of varying intensities and produce maximum storm surge products for the government, insurance companies, and general public (Glahn et al., 2009). In short, over the past two decades, a series of comprehensive risk assessment models have been developed abroad based on the quantitative assessment of marine dynamic disaster risk and vulnerability, which can be used for economic loss assessment, disaster reduction benefit analysis, disaster prevention, mitigation strategy formulation, and so on.

China is one of the most marine-disaster-prone countries in the world. Marine disasters result in huge hindrances to economic development and social harmony. In recent decades, China has made substantial progress in marine model forecasting and early warning technology supported by national scientific and technological research. Many researchers have developed and applied marine dynamic disaster early warning and forecasting systems using model forecasting, remote sensing, and geographic information systems (GISs). However, the content of this research has been limited to the assessment of individual disasters, such as ocean waves or storm surges, and lacks the investigation of massive marine dynamic disasters such as storm surge-wave-tidal coupling enhancement effects. At present, China is still in its infancy as far as research on vulnerability and risk assessment of inshore

\footnotetext{
* Corresponding author: yjhou@qdio.ac.cn
} 
disasters is concerned. Disaster risk assessment and the ability to make emergency decisions cannot meet the needs of disaster prevention and mitigation management. Future work should focus on disaster model building, as well as other systematic and quantitative research of marine dynamic disaster. The quantitative assessment of the vulnerability of typical coastal areas affected by marine dynamic disasters remains a significant challenge for comprehensive risk assessment (Shi et al., 2013).

In 2016, the Marine Environment Security Platform of the National Key Research and Development Program of China established a project entitled "Severe marine dynamic disasters: causing mechanism, risk assessment, response technology, and demonstration application" (No. 2016YFC1402000). This project has developed a complete research chain of "characteristic mechanismrisk assessment-assessment model-emergency technology-application demonstration." Through research on the characteristics of major dynamic disasters such as storm surges, sea waves, sea ice, and tsunamis, as well as the action mechanisms on inshore disaster-bearing bodies, the vulnerability assessment index system along with a dynamic disaster risk assessment model was established. On this basis, research on disaster prevention and control, emergency response technology, and disaster prevention standards was carried out to form a systematic emergency plan and application service platform for dealing with various major marine dynamic disasters. The articles in this special issue describe some of the research endeavors supported by this project.

Typhoon waves are one of the major marine disasters that affect China. Numerical models, such as the third-generation model SWAN and WAVEWATCH III, have become indispensable tools for studying these waves. It is well known that there are variable parameters and different choices of source schemes in models, all of which may significantly influence the simulation of typhoon waves. Thus, these variables need to be carefully tested. Wang et al. (2019c) clarified the effect of the drag coefficient on a typhoon wave model; when using a new drag coefficient, the SWAN model performs better than it did using the original coefficient. Wang et al. (2019a) simulated the typhoon waves generated during three typhoons using the SWAN model and studied the influences of key factors such as wind input, white-capping, and bottom friction on the wave growth and dissipation processes.
Rogue waves also be studied using buoy data and numerical simulation in order to understand the sea state and corresponding nonlinearity of real-world rogue wave events (Jiang et al., 2019). Since surface wave-induced mixing plays an important role in the formation of the upper mixed layer, Yang et al. (2019c) designed tentative experiments to estimate the effects of the wave transport flux residue under typhoon conditions and found that both overwhelming dynamical mixing processes can significantly alter the coastal environment. These results provide a better understanding of typhoon wave characteristics and improve the capability of typhoon wave simulations.

Sea ice disasters are one of the principal natural hazards that affect the Bohai Sea of China. Because the formation of ice cover in a wave field has influential characteristics, the study of theoretical, observational, and numerical developments regarding wave propagation through ice-covered waters has accelerated in the last 20 years. Using observational data of the sea ice cycle in the coastal waters of Liaodong Bay, China, Shi et al. (2019) analyzed the characteristics of hydrology, meteorology, and sea ice thickness during the formation of sea ice, and explored the changes in the interrelationships among heat fluxes, waves, and sea ice under actual sea conditions. Yue et al. (2019) implemented an eddy viscosity wave-ice model in the SWAN model and then analyzed the sea ice effect on Bohai Sea surface waves based on hindcasted results.

The major marine threat to the low-lying coastal areas of China is storm surge, which accompanies typhoons or extratropical cyclones and can cause flooding, destruction of buildings, and loss of life (Ministry of Natural Resources of the People's Republic of China, 2018). Because storm surge processes are often accompanied by astronomical high tides and huge waves, it is very important to study their interactions when developing numerical simulations and investigating the characteristics of storm surges. Zhang et al. (2019) studied the tidesurge interaction in the South Yellow Sea using the ADCIRC model and found that this interaction is dominated by tidal modulation, and its magnitude varies greatly with tidal phase. A high-resolution, integrally-coupled ADCIRC+SWAN model was then used to study the characteristics of storm surgeassociated waves and tides in the Bohai Sea (Wang et al., 2019b) as well as the radial sand ridges of the southern Yellow Sea (Xiong et al., 2019). 
After revealing the characteristics of hydrodynamic disaster-causing factors, researchers wanted to determine the effects of existing marine dynamic disasters on offshore hazard-bearing bodies such as sea dikes. Based on comprehensive laboratory measurements, Liu et al. (2019a) further developed an empirical formula to compute the wave uplift force on horizontal panels using dimensionless analysis. A physical model test of the typical seawall section was then carried out under the dynamic coupling of storm surge and waves in order to study the underlying mechanisms involved (Pan et al., 2019). Sun et al. (2019) deduced a calculation equation for the stable thickness of the dry masonry block stone of inner slopes subjected to irregular waves, which is capable of functioning as an important reference for the structural design of dikes in China. Li et al. (2019) developed an operational forecasting system for sea dike risk in southern Zhejiang Province, South China, with the goal of preventing typhoon storm-surge damage.

In addition to the factors that cause marine dynamic disasters, the vulnerability of disaster-bearing bodies is also an important factor determining disaster losses. In order to study the vulnerability of disaster-bearing bodies, the basic information of the disaster-bearing bodies themselves should be obtained first; for this, the extraction of satellite remote sensing data is the most effective method. Liu et al. (2019c) used highresolution remote-sensing satellite GF-2 images to introduce a deep-learning richer convolutional features (RCF) network model to extract aquaculture area. They then used aquaculture density as an assessment index to determine the vulnerability of aquaculture areas on Sanduao Island, China. Yang et al. (2019a) proposed a framework of remote sensing techniques for the vulnerability assessment of marine disasters, especially those in cloudy coastal areas. A 2D numerical model based on the ADCIRC model was then established in order to evaluate the impact of a reclamation project on tidal and storm surge levels in Sanmen Bay, China (Yang et al., 2019b). Their results revealed the effects of shoreline relocation and topographic change on tidal heights.

In recent years, scientific research has entered the era of big data. The creation of methods for utilizing different data in quality control, data comprehensive analysis, and visual display is very meaningful work. This project also carried out a series of studies around the data of marine dynamic disasters. Qian et al. (2019) used hourly real-time ocean station observation data to investigate quality control techniques and methods for determining the most suitable quality control approach for the data collected at the Xiaomaidao observation station in Qingdao, China. The typhoon wind hazard risk for the city of Shenzhen was analyzed using a Monte-Carlo simulation and the YM wind field model (Guo et al., 2019). Liu et al. (2019b) investigated the distribution and zoning of risks from sea level rise across Shandong Province and conducted an assessment of those risks. Liu et al. (2019d) focused on improving the line integral convolution visualization technique and applied their methods to the case of a surface wave field in typhoon conditions.

We thank the National Key Research and Development Program of China's "Severe marine dynamic disasters: causing mechanism, risk assessment, response technology, and demonstration application" project (No. 2016YFC1402000) for financial support. In addition, this special issue would not have been possible without the dedication of and inspirational comments from the reviewers..

\section{References}

Blain C A, Westerink J J, Luettich R A. 1994. The influence of domain size on the response characteristics of a hurricane storm surge model. Journal of Geophysical Research, 99(C9): 18467.

DHI. 1996. User Guide and Reference Manual of MIKE21 (Coastal Hydraulics and Oceanography).

Glahn B, Taylor A, Kurkowski N et al. 2009. The role of the SLOSH model in National Weather Service storm surge forecasting. National Weather Digest, 33(1): 3-14.

Guo Y X, Hou Y J, Qi P. 2019. Analysis of typhoon wind hazard in Shenzhen City by Monte-Carlo Simulation. Journal of Oceanology and Limnology, 37(6): $1994-$ 2 013, https://doi.org/10.1007/s00343-019-8231-9.

Hubbert G D, Mcinnes K L. 1999. Modelling Storm Surges and Coastal Ocean Flooding/Modelling Coastal Sea Processes.

IPCC. 2014. Climate change 2014: synthesis report. In: Writing Team, Core, Pachauri R K, Meyer L A eds. Contribution of Working Groups I, II and III to the Fifth Assessment Report of the Intergovernmental Panel on Climate Change. IPCC, Geneva, Switzerland. p.151.

Jiang X J, Guan C L, Wang D L. 2019. Rogue waves during Typhoon Trami in the East China Sea. Journal of Oceanology and Limnology, 37(6): 1 817-1 836 , https:// doi.org/10.1007/s00343-019-8256-0.

Li T, Wang F D, Hou J M, Che Z M, Dong J X. 2019. Validation of an operational forecasting system of sea dike risk in the southern Zhejiang Province, South China. Journal of Oceanology and Limnology, 37(6): $1929-1$ 940, https:// doi.org/10.1007/s00343-019-8240-8. 
Liu Q J, Sun T T, Wang D T, Wei Z P. 2019a. Wave uplift force on horizontal panels: a laboratory study. Journal of Oceanology and Limnology, 37(6): 1 899-1 911, https:// doi.org/10.1007/s00343-019-8292-9.

Liu Q R, Li J, Ruan C Q, Yin Z H, Jiao Y, Sun Q, Lian X H, Zhong S. 2019b. Risk assessment and zoning of sea level rise in Shandong Province. Journal of Oceanology and Limnology, 37(6): 2 014-2 024, https://doi.org/10.1007/ s00343-019-8233-7.

Liu Y M, Yang X M, Wang Z H, Lu C, Li Z, Yang F S. 2019c. Aquaculture area extraction and vulnerability assessment in Sanduao based on richer convolutional features network model. Journal of Oceanology and Limnology, 37(6): 1 941-1 954, https://doi.org/10.1007/s00343-019-8265-z.

Liu Z D, Liu H X, Su T Y, Jia Z, Li X F, Zhou L, Song Z L. 2019d. Dynamic visual simulation of marine vector field based on LIC - a case study of surface wave field in typhoon condition. Journal of Oceanology and Limnology, 37(6): 2 025-2 036, https://doi.org/10.1007/s00343-0198263-1.

Pan J N, Wang S P, Sun T T, Chen M W, Wang D T. 2019. Experimental study on inner slope failure mechanism of seawall by coupling effect of storm surge and wave. Journal of Oceanology and Limnology, 37(6): 1912 1 920, https://doi.org/10.1007/s00343-019-8236-4.

Qian C C, Liu A C, Huang R, Liu Qingrong, Xu Wenkun, Zhong Shan, Yu Le. 2019. Quality control of marine big data - a case study of real-time observation station data in Qingdao. Journal of Oceanology and Limnology, 37(6): 1 983-1 993, https://doi.org/10.1007/s00343-019-8258-y.

Shi X W, Tan J, Guo Z X, Liu Q Z. 2013. A review of risk assessment of storm surge disaster. Advances in Earth Science, 28(8): 866-874.

Shi Y F, Yang Y Z, Teng Y, Sun M, Yun Shengjun. 2019. Mechanism of sea ice formation based on comprehensive observation data in Liaodong Bay, China. Journal of Oceanology and Limnology, 37(6): 1 846-1 856, https:// doi.org/10.1007/s00343-019-8269-8.

Sun T T, Liu Q J, Wang D T. 2019. Stable-thickness study of masonry block on the inner slope of dikes. Journal of Oceanology and Limnology, 37(6): 1 921-1 928, https:// doi.org/10.1007/s00343-019-8235-5.

Wang N, Hou Y J, Li S Q, Li R. 2019a. Numerical simulation and preliminary analysis of typhoon waves during three typhoons in the Yellow Sea and East China Sea. Journal of Oceanology and Limnology, 37(6): 1 805-1 816, https:// doi.org/10.1007/s00343-019-8260-4.

Wang Y P, Liu Y L, Mao X Y, Chi Y T, Jiang W S. 2019b. Long-term variation of storm surge-associated waves in the Bohai Sea. Journal of Oceanology and Limnology, 37(6): 1 868-1 878, https://doi.org/10.1007/s00343-019$8257-z$.

Wang Z F, Gong Y J, Cui J N, Dong S, Wu K J. 2019c. Effect of the drag coefficient on a typhoon wave model. Journal of Oceanology and Limnology, 37(6): 1 795-1 804, https:// doi.org/10.1007/s00343-019-8228-4.

Wilson A S, Chen T. 1997. Storm Surge Modeling in the United States Part2: Surge form Extratropical Cyclones.

Xiong M J, Zhang J S, Zhang W S, Yin C T. 2019. Heterogeneous tide-surge interaction during co-occurrence of tropical and extratropical cyclones in the radial sand ridges of the southern Yellow Sea. Journal of Oceanology and Limnology, 37(6): 1 879-1 898, https://doi.org/10.1007/ s00343-019-8264-0.

Yang F S, Yang X M, Wang Z H, Lu C, Li Z, Liu Y M. 2019a. Object-based classification of cloudy coastal areas using medium-resolution optical and SAR images for vulnerability assessment of marine disaster. Journal of Oceanology and Limnology, 37(6): 1 955-1 970, https:// doi.org/10.1007/s00343-019-8266-y.

Yang W K, Feng X R, Yin B S. 2019b. The impact of coastal reclamation on tidal and storm surge level in Sanmen Bay, China. Journal of Oceanology and Limnology, 37(6): 1 971-1 982, https://doi.org/10.1007/s00343-019-8247-1.

Yang Y Z, Shi Y F, Yu C C, Teng Y, Sun M. 2019c. Study on surface wave-induced mixing of transport flux residue under typhoon conditions. Journal of Oceanology and Limnology, 37(6): 1 837-1 845, https://doi.org/10.1007/ s00343-019-8268-9.

Yue C, Li J K, Guan C L, Lian X H, Wu K J. 2019. Surface wave simulation during winter with sea ice in the Bohai Sea. Journal of Oceanology and Limnology, 37(6): 1857 1 867, https://doi.org/10.1007/s00343-019-8253-3.

Zhang W S, Teng L, Zhang J S, Xiong M J, Yin C T. 2019. Numerical study on effect of tidal phase on storm surge in the South Yellow Sea. Journal of Oceanology and Limnology, 37(6): 2 037-2 055, https://doi.org/10.1007/ s00343-019-8277-8. 